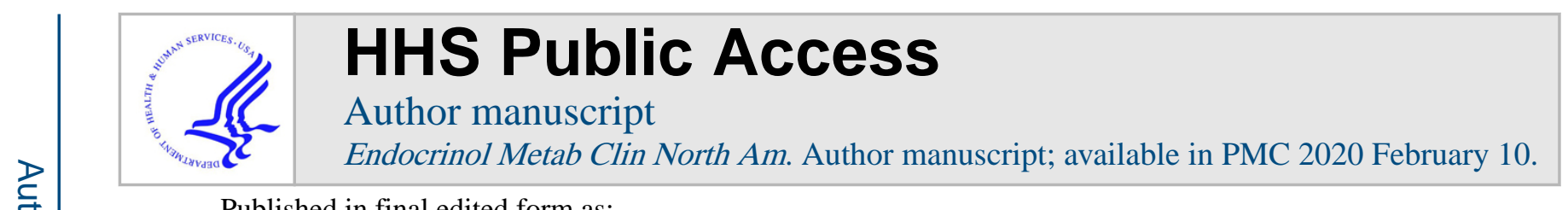

Published in final edited form as:

Endocrinol Metab Clin North Am. 2019 September ; 48(3): 479-493. doi:10.1016/j.ecl.2019.05.001.

\title{
Gestational Diabetes Mellitus
}

\author{
Emily D. Szmuilowicz, MD, MSa, Jami L. Josefson, MD, MS ${ }^{b}$, Boyd E. Metzger, MDc, ${ }^{*}$ \\ aDivision of Endocrinology, Metabolism and Molecular Medicine, Department of Medicine, \\ Northwestern University Feinberg School of Medicine, 645 North Michigan Avenue, 530-24, \\ Chicago, IL 60611, USA
}

bDivision of Endocrinology, Department of Pediatrics, Northwestern University Feinberg School of Medicine, Ann and Robert H. Lurie Children's Hospital of Chicago, 225 East Chicago Avenue, Box 54, Chicago, IL 60611, USA

'Division of Endocrinology, Metabolism and Molecular Medicine, Department of Medicine, Northwestern University Feinberg School of Medicine, Tarry Building, Room 12-703, 300 East Superior, Chicago, IL 60611, USA

\section{Keywords}

Gestational diabetes mellitus; Pregnancy; Diagnosis; Offspring; Outcomes; Treatment

\section{DEFINITION, DIAGNOSIS, DETECTION, AND PREVALENCE}

\section{Background}

The first diagnostic criteria for gestational diabetes mellitus (GDM) were published by O'Sullivan and Mahan 55 years ago. ${ }^{1}$ The criteria were developed from results of a 100-g oral glucose tolerance test (OGTT) during pregnancy in an unselected group of pregnant women (752 in total) receiving antenatal care at the Boston City Hospital. The mean and standard deviation (SD) of the venous whole blood glucose concentrations for each sample, fasting and 1, 2, and 3 hours after consumption of the glucose load, were calculated. Values equal to or greater than 2 SD above the mean were considered abnormal, and it was arbitrarily decided that for the test to be called abnormal, 2 or more values should be elevated. These test criteria when applied to 1013 women followed serially for 8 years after having a 100-g OGTT during pregnancy were strongly associated with the development of diabetes during follow-up. Glucose concentrations were later extrapolated from the whole blood values measured in this study to approximate plasma glucose values for contemporary analytical methods.

In 1978, the American College of Obstetricians and Gynecologists (ACOG) recommended screening pregnant women for diabetes among individuals with historical risk factors for diabetes $^{2}$ using an OGTT interpreted by the criteria of O'Sullivan and Mahan ${ }^{1}$ or Mestman and colleagues. ${ }^{3}$ In 1979, the National Diabetes Data Group (NDDG) ${ }^{4}$ published guidelines

*Corresponding author. bem@northwestern.edu.

Disclosure Statement: None. 
for the classification of diabetes and various categories of glucose intolerance including gestational diabetes, which was restricted to women in whom the "onset or recognition of diabetes or impaired glucose tolerance occurred during pregnancy." This subsequently became the standard definition of GDM. Interpretation of the OGTT using the criteria of O'Sullivan and Mahan ${ }^{1}$ extrapolated for plasma values was recommended because data were unavailable to link maternal glycemia to perinatal outcomes. The World Health Organization $(\mathrm{WHO})^{5,6}$ also published criteria for diabetes and impaired glucose tolerance during pregnancy that were the same as values used in nonpregnant persons. Many other detection strategies and diagnostic criteria for GDM have been published. ${ }^{7}$

\section{Gestational Diabetes Mellitus in the Twenty-first Century}

It has been well documented and generally accepted that women found to have GDM are at high risk for development of type 2 diabetes mellitus (T2DM) in subsequent years. ${ }^{1,8,9}$ Nevertheless, there was vigorous debate about the value of detecting and treating GDM that persisted into the twenty-first century. ${ }^{10}$ One issue was whether the adverse perinatal outcomes in pregnancies of women with hyperglycemia less than diagnostic of diabetes mellitus are independently associated with maternal glycemia or attributable to greater obesity, higher maternal age, more urinary tract infections, or social disadvantages. The second was whether treating hyperglycemia in women with GDM actually reduced adverse outcomes.

\section{Maternal glycemia and perinatal outcomes}

The Hyperglycemia and Adverse Pregnancy Outcome (HAPO) study, ${ }^{11}$ a multicenter, multinational, multiethnic group observational study addressed the first issue. In the HAPO study, more than 25,500 pregnant women at 15 centers in 9 countries consented to have a 75-g, 2-h OGTT at 24 to 32 weeks (mean 28) of gestation. Those with 1 or more OGTT values above or below predefined concentrations were excluded, as were those who delivered at a hospital other than where they entered the study. In the remainder, results of the OGTT were blinded to caregivers and participants, and all were given normal obstetric and neonatal care. The associations among fasting, 1-h and 2-h OGTT glucose concentrations, and 4 primary (birthweight and cord blood c-peptide each $>95$ th percentile and rates of primary cesarean delivery and clinically recognized neonatal hypoglycemia) and several secondary outcomes were examined in 23,316 pregnancies. As illustrated in Fig. 1, rates of each outcome increased as each OGTT value increased. The associations were continuous and linear in models adjusted for confounders, including maternal age, body mass index (BMI), and study field center. There were no obvious thresholds at which risks increased. Significant associations were also observed for secondary outcomes, although these tended to be weaker.

\section{Results of treating gestational diabetes mellitus}

The impact of treating "mild" gestational diabetes has been examined in 2 randomized controlled trials (RCT). The Australian Carbohydrate Intolerance Study in Pregnant Women (ACHOIS) trial ${ }^{12}$ reported study outcomes in 1000 women who met the then standard WHO criteria for gestational diabetes, 5,6 that is, fasting plasma glucose (FPG) $<140 \mathrm{mg} / \mathrm{dL}$ and 2-h OGTT value between 140 and $199 \mathrm{mg} / \mathrm{dL}$. The Maternal-Fetal Medicine Units Network 
Study ${ }^{13}$ reported perinatal outcomes in 958 participants who met the Carpenter-Coustan criteria for gestational diabetes ${ }^{14}$ whose FPG was less than $95 \mathrm{mg} / \mathrm{dL}$. Although the diagnostic tests and criteria used in the 2 RCTs differed substantially, treatment outcomes were quite similar (Table 1), providing strong evidence that treating GDM can indeed reduce adverse pregnancy outcomes.

\section{Diagnostic criteria, detection, and prevalence of gestational diabetes mellitus}

The International Association of Diabetes and Pregnancy Study Groups (IADPSG) recommended criteria for the diagnosis of GDM that are based on the HAPO study results, supported by other evidence. ${ }^{15}$ The IADPSG diagnostic thresholds are the first criteria based on risks of adverse perinatal outcomes, rather than risk of subsequent development of maternal diabetes ${ }^{1}$ or by applying thresholds that define impaired glucose tolerance outside of pregnancy. 5,6

The 1-step approach to detection and diagnosis of GDM recommended by the IADPSG ${ }^{15}$ results in a higher prevalence of GDM than other strategies, particularly the 2-step approaches based on the original O'Sullivan-Mahan criteria. ${ }^{1}$ The fact that the IADPSG criteria for GDM require 1 or more rather than 2 or more OGTT values equal to or greater than defined threshold concentrations is a major reason for the higher prevalence rates. When the IADPSG criteria were applied to the HAPO study cohort retrospectively, $17.8 \%$ had GDM, and there was substantial center-to-center variation in prevalence. ${ }^{16}$ Given the high rates of combined T2DM and prediabetes and obesity in nonpregnant women of reproductive age (Table 2), it is not unexpected that rates of GDM are now much higher than when GDM was first recognized. ${ }^{1}$

\section{Current Recommendations}

The WHO has adopted the IADPSG criteria for GDM. ${ }^{17}$ However, an independent panel of health professionals and public representatives appointed by the National Institutes of Health did not. ${ }^{18}$ ACOG continues to recommend the traditional approach to detection and diagnosis of GDM. The high prevalence of GDM with associated costs of providing treatment and the lack of RCT data indicating benefit of treating individuals who meet IADPSG but not Carpenter-Coustan criteria for GDM (one or more values equal to or greater than the diagnostic threshold rather than two) contributed to the panel's conclusions. Thus, multiple criteria for the diagnosis of GDM are now accepted for use in the United States (Table 3). It remains to be seen what impact reports of benefit from treating GDM meeting IADPSG but not Carpenter-Coustan criteria for $\mathrm{GDM}^{19}$ have on clinical practice.

\section{OFFSPRING OUTCOMES}

Perinatal and long-term offspring outcomes following exposure to diabetes in pregnancy are directly related to glycemic control during pregnancy. ${ }^{11,20-22}$ Despite recent improvements in maternal glycemic control and a reduction in the frequency of perinatal complications, the prevalence of adverse pregnancy outcomes continues to be higher than the general population. ${ }^{12,23}$ 


\section{Adverse Outcomes by Age Group}

Potential adverse offspring outcomes vary by age group (Table 4) and avoidance of one outcome does not indicate reduction in risk of other adverse outcomes. ${ }^{21,24,25}$ It is necessary to emphasize that most studies reporting short-term and long-term offspring outcomes were composed of mothers with some or all types of diabetes in pregnancy.

\section{Neonatal Complications}

Birth complications, including high risk of cesarean delivery, shoulder dystocia, and birth injury, are often due to a large-size fetus. The Pedersen hypothesis, ${ }^{26}$ which was later expanded on by Freinkel, ${ }^{27}$ proposed that increased fetal size is the direct result of excessive circulating maternal glucose and other fuels that cross the placenta to provide the fetus with energy substrates. The fetus responds to excessive energy substrates by producing higher amounts of insulin, that is, fetal hyperinsulinemia, which then leads to a number of consequences, notably excessive fetal growth and subsequent large for gestational age birth size. In pregnancies complicated by diabetes, fetal insulin binds to the insulinlike growth factor 1 receptor with affinity equal to the insulin receptor. ${ }^{28}$ Growth factors, not growth hormone, are key promoters of fetal growth.

A relative fetal hypoxia occurs in utero, which may underlie the risk of stillbirth and birth asphyxia. ${ }^{29}$ This hypoxia induces increased erythropoietin production and subsequent polycythemia and hyperbilirubinemia in the neonate. ${ }^{30}$ Fetal hyperinsulinemia alters lung surfactant synthesis, and this predisposes to respiratory distress syndrome, ${ }^{31}$ a lifethreatening condition in the neonatal period that leads to significant morbidity and admission to the neonatal intensive care unit.

Hypoglycemia of the neonate is a well-recognized complication in offspring of women with GDM. ${ }^{32}$ When the constant maternal flow of glucose is abruptly halted at delivery, the relative fetal hyperinsulinemia continues and uses available neonatal glucose stores, which can lead to neonatal hypoglycemia. Preventive strategies to diagnose and treat neonatal hypoglycemia include blood glucose monitoring protocols and frequent feedings in those neonates deemed at increased risk. In the majority of instances, the condition is self-limited as the hyperinsulinemia resolves.

Large size at birth is common in offspring born to women with GDM. Numerous studies in this population have demonstrated that the increased birth weight is due to higher amounts of fat mass as opposed to fat-free muscle mass. ${ }^{33,34}$

\section{Childhood Complications}

Only recently has the finding of excessive adiposity among GDM offspring been documented in childhood. ${ }^{21}$ Other long-term complications are insulin resistance, impaired glucose tolerance, and T2DM, collectively termed disorders of glucose metabolism, and psychological and developmental effects that may be related to neonatal hypoglycemia.

Risk of impaired neurodevelopmental outcomes among offspring of mothers with GDM has been studied in several cohorts. ${ }^{35}$ Expressive language, memory recall, and facial recognition are developmental areas studied in which offspring of mothers with GDM differ 
from controls not exposed to GDM. ${ }^{36,37}$ An increased risk of autism spectrum disorders in offspring of mothers with GDM also has been documented. ${ }^{38}$

The 2 well-described long-term follow-up studies of diabetes in pregnancy, in the Pima Indian population and at Northwestern University, documented higher rates of obesity, as measured by weight alone, among children exposed to diabetes in pregnancy compared with children not exposed. ${ }^{22,39}$ Large birth weight was not a universal finding among these offspring. ${ }^{40}$ Interestingly, the timing of obesity development was different in these 2 cohorts: among Pima Indians, offspring of diabetic mothers weighed more compared with offspring of nondiabetic mothers at every age throughout childhood, ${ }^{40}$ whereas in the Northwestern cohort, obesity among offspring of mothers with diabetes emerged in the peri-pubertal years. 41 Studies among sibling pairs in the Pima Indian population born before versus after the maternal diagnosis of diabetes provide convincing evidence that the diabetic intrauterine environment underlies the elevated obesity risk, separate or perhaps additive to the genetic risk. ${ }^{42}$ This finding of increased obesity rates among the younger siblings born after the maternal development of diabetes was duplicated in a study of Swedish male siblings. ${ }^{43}$

Disentangling the independent effects of maternal hyperglycemia and obesity on offspring obesity risk is important to guide preventive strategies. The HAPO Followup Study (FUS) demonstrated that offspring exposed to mild, untreated maternal hyperglycemia had higher rates of adiposity at a mean age of 11.4 years. ${ }^{21}$ These results were somewhat attenuated by maternal BMI. This study, along with others, ${ }^{44,45}$ extended earlier findings of higher weight among offspring of mothers with diabetes by demonstrating specific increases in adipose tissue using several methodologies, including skinfold thicknesses with calipers, waist circumference, dual-energy X-ray absorptiometry, and air displacement plethysmography. Higher adiposity, as opposed to higher weight, is an important risk factor for cardiometabolic diseases and early death.

HAPO is unique compared with other studies of hyperglycemia in pregnancy in that the data are not confounded by maternal treatment. Another novel finding of the HAPO FUS was that maternal hyperglycemia during pregnancy was independently associated with risk of abnormal glucose tolerance in the offspring. ${ }^{46}$ In addition, disposition index, a predictor of T2DM, was significantly lower among offspring of mothers with GDM. ${ }^{47}$ Several studies of T2DM in youth found high rates of exposure to maternal GDM. ${ }^{47,48}$ However, the a priori associations in HAPO FUS between maternal GDM and offspring disorders of glucose metabolism provide further convincing evidence that in utero exposure to hyperglycemia adversely programs the fetal pancreas and increases future risk of disorders of glucose metabolism.

\section{Summary}

With the increasing prevalence of obesity among women of reproductive age, rates of GDM will continue to increase. Most concerning is the perpetuation of the cycle of diabetes between mother and child. Increased rates of adiposity and disorders of glucose metabolism in peripubertal offspring of mothers with mild, untreated GDM have been demonstrated. ${ }^{21}$ In studies of young children whose mothers had mild GDM, there was no difference in obesity rates in the offspring of treated mothers compared with untreated mothers. ${ }^{49}$ 
However, it remains to be determined whether increased obesity rates will emerge in the untreated offspring in later childhood or adolescence.

In summary, optimizing diagnosis and treatment of GDM is a necessary strategy to prevent adverse metabolic health outcomes in offspring.

\section{TREATMENT}

\section{Lifestyle Interventions}

Medical nutrition therapy (MNT) is a cornerstone of therapy for all women with GDM, and approximately $80 \%$ to $90 \%$ of women are able to meet therapeutic targets with MNT alone. 12,13 Multiple benefits have been attributed to lifestyle interventions, including decreased risk of macrosomia, decreased neonatal adiposity, and increased likelihood to achieve postpartum weight goals. ${ }^{12,13,50}$ Generally women are advised to eat 3 small to moderatesized meals and 2 to 3 snacks that are balanced in whole-grain carbohydrates, protein, and unsaturated fats. Because carbohydrate intolerance can be more marked at the morning meal, women are often advised to eat less carbohydrate at breakfast (for example, $30 \mathrm{~g}$ at breakfast compared with 45-60 $\mathrm{g}$ at lunch and dinner). Although evidence supporting a particular macronutrient distribution is sparse, ${ }^{51}$ benefits of a lowglycemic index diet have been demonstrated. ${ }^{52,53}$ Meal planning focuses not only on prescribed carbohydrate amounts and distribution, but also on pairing intake of carbohydrate with ingestion of lean protein and/or unsaturated fat at meals and snacks, to lessen the degree of postprandial carbohydrateinduced glycemic excursion. Women are frequently advised to consume a bedtime snack to counteract the greater tendency toward accelerated starvation and accompanying ketosis that characterizes the pregnant state and can emerge during the overnight fast. Stemming from literature suggesting adverse neurodevelopmental impact of gestational ketonemia, ${ }^{35}$ some centers advise women to monitor urine ketone levels to assess for deficiency in carbohydrate intake; when ketonuria occurs, women are advised to augment nutritional intake.

Moderate physical activity is also recommended as part of the treatment program. Generally, women with GDM are advised to obtain 30 minutes of moderate-intensity aerobic exercise on at least 5 days per week or a minimum of 150 minutes over the course of the week, ${ }^{54}$ similar to recommendations for nonpregnant people with DM. Although studies evaluating glycemic impact of exercise in GDM are sparse, exercise has been shown to improve fasting and postprandial glycemia in GDM. ${ }^{55}$ Acute bouts of moderate-intensity walking after eating improved postprandial glucose control for up to 3 hours after the meal,${ }^{56}$ and postmeal walking is frequently recommended when there are no contraindications to physical activity. ${ }^{54}$

\section{Pharmacologic Therapy}

Insulin-When glycemic goals are not met with MNT, pharmacologic therapy is added. Insulin therapy is considered the first-line pharmacologic therapy for GDM, as it does not cross the placenta to a significant degree. ${ }^{54,57}$ Fasting hyperglycemia is treated with basal (long-acting or intermediate-acting) insulin, and postprandial hyperglycemia is treated with prandial (rapid-acting) insulin. Basal and prandial insulin may be used separately or in 
combination, depending on the individual glycemic profile. General total daily insulin requirements by gestational age are shown in Table 5, but in practice, individual insulin requirements vary significantly, with some women achieving glycemic targets at significantly lower doses and others requiring significantly more. Weekly (or more frequent) insulin dose adjustments are made based on self-monitored glycemic patterns.

NPH has long been considered the mainstay of basal insulin treatment during pregnancy due to its long track record of safety and effectiveness, but more recently, basal insulin analogs have gained increasing acceptance. Insulin detemir was shown to be noninferior to NPH in pregnancies complicated by type 1 diabetes mellitus (T1DM) ${ }^{58}$ In addition, the rapid-acting insulin analogs aspart and lispro have acceptable safety and efficacy profiles in pregnancy. 59,60 Rapid-acting insulin analogs are generally preferred over regular insulin for prandial coverage because of their more rapid onset of action, enabling administration in closer proximity to the meal and improved postprandial glycemia.

Oral agents-At the current time, treatment of GDM with oral agents is controversial, and data on long-term outcomes for the offspring are lacking.

Glyburide: Although glyburide was previously thought not to cross the placenta in significant amounts, ${ }^{61}$ more recent studies using more sensitive assays have demonstrated significant and highly variable transplacental transfer of glyburide. ${ }^{62,63}$ Although similar glycemic control has been reported with glyburide compared with insulin use, ${ }^{61}$ recent data have raised concern about increased risk of adverse outcomes with use of glyburide compared with insulin, including increased risk of macrosomia ${ }^{64}$ and neonatal hypoglycemia. ${ }^{64,65}$ A recent RCT failed to show noninferiority of glyburide compared with insulin in the reduction of perinatal complications. ${ }^{66}$ Long-term safety data among offspring prenatally exposed to glyburide are lacking.

Metformin: Metformin freely crosses the placenta, and the fetal metformin concentration is similar to or higher than the maternal concentration. ${ }^{67,68}$ Metformin compared with insulin use has been associated with mixed outcomes; for example, less maternal weight gain, lower postprandial glucose, and less pregnancy-induced hypertension, but higher rates of preterm birth. ${ }^{64}$ Although short-term studies of neurodevelopmental outcomes among metforminexposed offspring have been reassuring, ${ }^{69}$ the potential long-term effects on fetal developmental metabolic programming and the long-term metabolic consequences in the offspring are currently unknown. ${ }^{70}$ Notably, 2 studies reported that metformin-exposed children of mothers with polycystic ovary syndrome or GDM were found to weigh more at $4^{71}$ and 9 years of age. ${ }^{72}$ It is also worth noting the significant treatment failure rate observed with metformin use: up to one-half of women treated with metformin still required adjunctive insulin therapy.64,73

\section{Summary}

At the current time, the comparative advantages and disadvantages of insulin, glyburide, and metformin in the treatment of GDM are uncertain, especially with regard to long-term outcomes in prenatally exposed offspring. Embodying these uncertainties, current expert 
guidelines provide contradictory recommendations. ACOG ${ }^{54}$ and the American Diabetes Association (ADA) ${ }^{57}$ both recommend insulin as the preferred first-line pharmacologic therapy for GDM, whereas the Society for Maternal Fetal Medicine advises that metformin is a reasonable and safe first-line pharmacologic alternative to insulin. ${ }^{74} \mathrm{ACOG}^{54}$ notes that oral agents (with metformin preferred over glyburide) are a reasonable alternative for women unable or unwilling to use insulin.

In our opinion, at the current time, insulin remains the first-line treatment for GDM due to the known transplacental passage of oral agents, the absence of long-term safety data in prenatally exposed offspring, and concerns about nonequivalent perinatal outcomes. This position is consistent with the ADA's current clinical practice recommendations. ${ }^{57}$ Women should be informed that oral agents cross the placenta and that, although no prohibitive adverse fetal outcomes have been observed in short-term studies, long-term safety data are lacking.

\section{Glucose Monitoring}

Women are asked to monitor capillary blood glucose fasting and either 1 or 2 hours after meals (with selective use of pre-lunch and pre-dinner values) to guide insulin dose adjustments.

Although continuous glucose monitoring (CGM) has been shown to improve glycemic and neonatal outcomes in pregnancies complicated by T1DM, ${ }^{75}$ studies evaluating CGM use in GDM are limited. Although improved glycemic control and pregnancy outcomes have been reported with CGM use among women with GDM, ${ }^{76}$ these findings have not been consistent. ${ }^{77}$ Larger studies evaluating the role of CGM use in pregnancies complicated by GDM are needed.

\section{Glycemic Goals}

The second and third trimesters of pregnancy are characterized by a progressive increase in insulin resistance and therefore insulin requirements because of the gradual increase in placental elaboration of diabetogenic hormones over the course of gestation. As a result, frequent glucose monitoring and therapeutic adjustments are typically required to achieve glycemic targets.

Glycemic targets are as follows ${ }^{54,57}$ :

- $\quad$ Fasting less than $95 \mathrm{mg} / \mathrm{dL}(5.3 \mathrm{mmol} / \mathrm{L})$ and either

- $\quad$ One-hour postprandial less than $140 \mathrm{mg} / \mathrm{dL}(7.8 \mathrm{mmol} / \mathrm{L})$ or

- $\quad$ Two-hour postprandial less than $120 \mathrm{mg} / \mathrm{dL}(6.7 \mathrm{mmol} / \mathrm{L})$

Women are advised to submit weekly glucose updates. Typically, changes to the therapeutic regimen (addition of insulin for those treated with lifestyle modifications only, or adjustment of the insulin regimen for those already taking insulin) are recommended when $20 \%$ to $25 \%$ of glucose values (e.g., 2 days out of 7) at a particular time point (fasting and/or following a particular meal) are above target despite adherence to the existing treatment regimen, or if hypoglycemia occurs. Serial adjustments to the basal and/or prandial insulin doses are 
guided by patterns in self-monitored glucose levels, individually or in combination. In addition to insulin doses, ongoing attention is paid to the impact on glycemic patterns of other factors, including timing of prandial insulin administration in relation to food intake, ${ }^{78}$ meal composition/food choices, and physical activity.

\section{REFERENCES}

1. O'Sullivan JB, Mahan CM. Criteria for the oral glucose tolerance test in pregnancy. Diabetes 1964;13:278-85. [PubMed: 14166677]

2. American College of Obstetricians and Gynecologists. Management of diabetes mellitus in pregnancy Technical Bulletin no. 48. Washington, DC: ACOG; 1978.

3. Mestman JH, Anderson GV, Barton P. Carbohydrate metabolism in pregnancy. A study of 658 patients with the use of the oral glucose tolerance test and the prednisolone glucose tolerance test. Am J Obstet Gynecol 1971;109(1):41-5. [PubMed: 5099607]

4. Classification and diagnosis of diabetes mellitus and other categories of glucose intolerance. National Diabetes Data Group. Diabetes 1979;28(12):1039-57. [PubMed: 510803]

5. WHO Expert Committee on Diabetes Mellitus: second report. World Health Organ Tech Rep Ser 1980;646:1-80. [PubMed: 6771926]

6. Diabetes mellitus. Report of a WHO Study Group. World Health Organ Tech Rep Ser 1985;727:1113. [PubMed: 3934850]

7. Cutchie WA, Cheung NW, Simmons D. Comparison of international and New Zealand guidelines for the care of pregnant women with diabetes. Diabet Med 2006; 23(5):460-8. [PubMed: 16681554]

8. Kim C, Newton KM, Knopp RH. Gestational diabetes and the incidence of type 2 diabetes: a systematic review. Diabetes Care 2002;25(10):1862-8. [PubMed: 12351492]

9. Metzger BE. Long-term outcomes in mothers diagnosed with gestational diabetes mellitus and their offspring. Clin Obstet Gynecol 2007;50(4):972-9. [PubMed: 17982340]

10. Metzger BE, Buchanan TA. Gestational diabetes In: Cowie CC, Casagrande SS, Menke A, et al., editors. Diabetes in America. 3rd edition Bethesda (MD): National Institutes of Health; 2018 p. 117.

11. Metzger BE, Lowe LP, Dyer AR, et al. Hyperglycemia and adverse pregnancy outcomes. N Engl J Med 2008;358(19):1991-2002. [PubMed: 18463375]

12. Crowther CA, Hiller JE, Moss JR, et al. Effect of treatment of gestational diabetes mellitus on pregnancy outcomes. N Engl J Med 2005;352(24):2477-86. [PubMed: 15951574]

13. Landon MB, Spong CY, Thom E, et al. A multicenter, randomized trial of treatment for mild gestational diabetes. N Engl J Med 2009;361(14):1339-48. [PubMed: 19797280]

14. Carpenter MW, Coustan DR. Criteria for screening tests for gestational diabetes. Am J Obstet Gynecol 1982;144(7):768-73. [PubMed: 7148898]

15. International Association of Diabetes Pregnancy Study Groups Consensus Panel, Metzger BE, Gabbe SG, Persson B, et al. International Association of Diabetes and pregnancy study groups recommendations on the diagnosis and classification of hyperglycemia in pregnancy. Diabetes Care 2010;33(3):676-82. [PubMed: 20190296]

16. Sacks DA, Hadden DR, Maresh M, et al. Frequency of gestational diabetes mellitus at collaborating centers based on IADPSG consensus panel-recommended criteria: the Hyperglycemia and Adverse Pregnancy Outcome (HAPO) Study. Diabetes Care 2012;35(3):5268. [PubMed: 22355019]

17. Diagnostic criteria and classification of hyperglycaemia first detected in pregnancy: a World Health Organization guideline. Diabetes Res Clin Pract 2014; 103(3):341-63. [PubMed: 24847517]

18. National Institutes of Health consensus development conference statement: diagnosing gestational diabetes mellitus, March 4-6, 2013. Obstet Gynecol 2013; 122 (2 Pt 1):358-69. [PubMed: 23969806]

19. Yang X, Tian H, Zhang F, et al. A randomised translational trial of lifestyle intervention using a 3tier shared care approach on pregnancy outcomes in Chinese women with gestational diabetes mellitus but without diabetes. J Transl Med 2014;12:290. [PubMed: 25349017] 
20. Falavigna M, Schmidt MI, Trujillo J, et al. Effectiveness of gestational diabetes treatment: a systematic review with quality of evidence assessment. Diabetes Res Clin Pract 2012;98(3):396405. [PubMed: 23031412]

21. Lowe WL Jr, Scholtens DM, Lowe LP, et al. Association of gestational diabetes with maternal disorders of glucose metabolism and childhood adiposity. JAMA 2018;320(10):1005-16. [PubMed: 30208453]

22. Pettitt DJ, Knowler WC. Long-term effects of the intrauterine environment, birth weight, and breast-feeding in Pima Indians. Diabetes Care 1998;21(Suppl 2): B138-41. [PubMed: 9704241]

23. Wexler DJ, Powe CE, Barbour LA, et al. Research gaps in gestational diabetes mellitus: executive summary of a National Institute of Diabetes and Digestive and Kidney Diseases workshop. Obstet Gynecol 2018;132(2):496-505. [PubMed: 29995731]

24. Schaefer-Graf UM, Buchanan TA, Xiang A, et al. Patterns of congenital anomalies and relationship to initial maternal fasting glucose levels in pregnancies complicated by type 2 and gestational diabetes. Am J Obstet Gynecol 2000;182(2): 313-20. [PubMed: 10694330]

25. Wendland EM, Torloni MR, Falavigna M, et al. Gestational diabetes and pregnancy outcomes-a systematic review of the World Health Organization (WHO) and the International Association of Diabetes in Pregnancy Study Groups (IADPSG) diagnostic criteria. BMC Pregnancy Childbirth 2012;12:23. [PubMed: 22462760]

26. Pedersen J Weight and length at birth of infants of diabetic mothers. Acta Endocrinol (Copenh) 1954;16(4):330-42. [PubMed: 13206643]

27. Freinkel N Banting lecture 1980. of pregnancy and progeny. Diabetes 1980; 29(12):1023-35. [PubMed: 7002669]

28. Hiden U, Glitzner E, Hartmann M, et al. Insulin and the IGF system in the human placenta of normal and diabetic pregnancies. J Anat 2009;215(1):60-8. [PubMed: 19467150]

29. Dudley DJ. Diabetic-associated stillbirth: incidence, pathophysiology, and prevention. Obstet Gynecol Clin North Am 2007;34(2):293-307, ix. [PubMed: 17572273]

30. Salvesen DR, Brudenell JM, Snijders RJ, et al. Fetal plasma erythropoietin in pregnancies complicated by maternal diabetes mellitus. Am J Obstet Gynecol 1993;168(1 Pt 1):88-94. [PubMed: 8420356]

31. Moore TR. A comparison of amniotic fluid fetal pulmonary phospholipids in normal and diabetic pregnancy. Am J Obstet Gynecol 2002;186(4):641-50. [PubMed: 11967485]

32. Metzger BE, Persson B, Lowe LP, et al. Hyperglycemia and adverse pregnancy outcome study: neonatal glycemia. Pediatrics 2010;126(6):e1545-52. [PubMed: 21078733]

33. Sewell MF, Huston-Presley L, Super DM, et al. Increased neonatal fat mass, not lean body mass, is associated with maternal obesity. Am J Obstet Gynecol 2006;195(4):1100-3. [PubMed: 16875645]

34. HAPO Study Cooperative Research Group. Hyperglycemia and Adverse Pregnancy Outcome (HAPO) Study: associations with neonatal anthropometrics. Diabetes 2009;58(2):453-9. [PubMed: 19011170]

35. Rizzo TA, Dooley SL, Metzger BE, et al. Prenatal and perinatal influences on longterm psychomotor development in offspring of diabetic mothers. Am J Obstet Gynecol 1995;173(6): 1753-8. [PubMed: 8610757]

36. Fraser A, Nelson SM, Macdonald-Wallis C, et al. Associations of existing diabetes, gestational diabetes, and glycosuria with offspring IQ and educational attainment: the Avon Longitudinal Study of Parents and Children. Exp Diabetes Res 2012;2012:963735. [PubMed: 22927834]

37. Dionne G, Boivin M, Seguin JR, et al. Gestational diabetes hinders language development in offspring. Pediatrics 2008;122(5):e1073-9. [PubMed: 18977957]

38. Nahum Sacks K, Friger M, Shoham-Vardi I, et al. Prenatal exposure to gestational diabetes mellitus as an independent risk factor for long-term neuropsychiatric morbidity of the offspring. Am J Obstet Gynecol 2016;215(3):380.e1-7. [PubMed: 27018463]

39. Silverman BL, Rizzo TA, Cho NH, et al. Long-term effects of the intrauterine environment. The Northwestern University Diabetes in Pregnancy Center. Diabetes Care 1998;21(Suppl 2):B142-9. [PubMed: 9704242]

40. Pettitt DJ, Knowler WC, Bennett PH, et al. Obesity in offspring of diabetic Pima Indian women despite normal birth weight. Diabetes Care 1987;10(1):76-80. [PubMed: 3568964] 
41. Silverman BL, Rizzo T, Green OC, et al. Long-term prospective evaluation of offspring of diabetic mothers. Diabetes 1991;40(Suppl 2):121-5. [PubMed: 1748240]

42. Dabelea D, Hanson RL, Lindsay RS, et al. Intrauterine exposure to diabetes conveys risks for type 2 diabetes and obesity: a study of discordant sibships. Diabetes 2000;49(12):2208-11. [PubMed: 11118027]

43. Lawlor DA, Lichtenstein P, Langstrom N. Association of maternal diabetes mellitus in pregnancy with offspring adiposity into early adulthood: sibling study in a prospective cohort of 280,866 men from 248,293 families. Circulation 2011; 123(3):258-65. [PubMed: 21220735]

44. Zhao P, Liu E, Qiao Y, et al. Maternal gestational diabetes and childhood obesity at age 9-11: results of a multinational study. Diabetologia 2016;59(11):2339-48. [PubMed: 27510911]

45. Vohr BR, McGarvey ST, Tucker R. Effects of maternal gestational diabetes on offspring adiposity at 4-7 years of age. Diabetes Care 1999;22(8):1284-91. [PubMed: 10480772]

46. Tam WH, Ma RCW, Ozaki R, et al. In utero exposure to maternal hyperglycemia increases childhood cardiometabolic risk in offspring. Diabetes Care 2017; 40(5):679-86. [PubMed: 28279981]

47. Holder T, Giannini C, Santoro N, et al. A low disposition index in adolescent offspring of mothers with gestational diabetes: a risk marker for the development of impaired glucose tolerance in youth. Diabetologia 2014;57(11):2413-20. [PubMed: 25168408]

48. Dabelea D, Mayer-Davis EJ, Lamichhane AP, et al. Association of intrauterine exposure to maternal diabetes and obesity with type 2 diabetes in youth: the SEARCH Case-Control Study. Diabetes Care 2008;31(7):1422-6. [PubMed: 18375420]

49. Landon MB, Rice MM, Varner MW, et al. Mild gestational diabetes mellitus and long-term child health. Diabetes Care 2015;38(3):445-52. [PubMed: 25414152]

50. Brown J, Alwan NA, West J, et al. Lifestyle interventions for the treatment of women with gestational diabetes. Cochrane Database Syst Rev 2017;(5):CD011970. [PubMed: 28472859]

51. Han S, Middleton P, Shepherd E, et al. Different types of dietary advice for women with gestational diabetes mellitus. Cochrane Database Syst Rev 2017;(2):CD009275. [PubMed: 28236296]

52. Viana LV, Gross JL, Azevedo MJ. Dietary intervention in patients with gestational diabetes mellitus: a systematic review and meta-analysis of randomized clinical trials on maternal and newborn outcomes. Diabetes Care 2014;37(12):3345-55. [PubMed: 25414390]

53. Wei J, Heng W, Gao J. Effects of low glycemic index diets on gestational diabetes mellitus: a metaanalysis of randomized controlled clinical trials. Medicine (Baltimore) 2016;95(22):e3792. [PubMed: 27258511]

54. Committee on Practice Bulletins-Obstetrics. ACOG Practice Bulletin No. 190: gestational diabetes mellitus. Obstet Gynecol 2018;131(2):e49-64. [PubMed: 29370047]

55. Harrison AL, Shields N, Taylor NF, et al. Exercise improves glycaemic control in women diagnosed with gestational diabetes mellitus: a systematic review. J Physiother 2016;62(4):188-96. [PubMed: 27637772]

56. Coe DP, Conger SA, Kendrick JM, et al. Postprandial walking reduces glucose levels in women with gestational diabetes mellitus. Appl Physiol Nutr Metab 2018;43(5):531-4. [PubMed: 29272606]

57. American Diabetes Association. Standards of medical care in diabetes - 2019. Diabetes Care 2019;42(Supplement 1):S1-193. [PubMed: 30559224]

58. Mathiesen ER, Hod M, Ivanisevic M, et al. Maternal efficacy and safety outcomes in a randomized, controlled trial comparing insulin detemir with NPH insulin in 310 pregnant women with type 1 diabetes. Diabetes Care 2012;35(10):2012-7. [PubMed: 22851598]

59. Lv S, Wang J, Xu Y. Safety of insulin analogs during pregnancy: a meta-analysis. Arch Gynecol Obstet 2015;292(4):749-56. [PubMed: 25855052]

60. Durnwald CP, Landon MB. A comparison of lispro and regular insulin for the management of type 1 and type 2 diabetes in pregnancy. J Matern Fetal Neonatal Med 2008;21(5):309-13. [PubMed: 18446657]

61. Langer O, Conway DL, Berkus MD, et al. A comparison of glyburide and insulin in women with gestational diabetes mellitus. N Engl J Med 2000;343(16):1134-8. [PubMed: 11036118] 
62. Schwartz RA, Rosenn B, Aleksa K, et al. Glyburide transport across the human placenta. Obstet Gynecol 2015;125(3):583-8. [PubMed: 25730219]

63. Caritis SN, Hebert MF. A pharmacologic approach to the use of glyburide in pregnancy. Obstet Gynecol 2013;121(6):1309-12. [PubMed: 23812467]

64. Balsells M, Garcia-Patterson A, Sola I, et al. Glibenclamide, metformin, and insulin for the treatment of gestational diabetes: a systematic review and meta-analysis. BMJ 2015;350:h102. [PubMed: 25609400]

65. Song R, Chen L, Chen Y, et al. Comparison of glyburide and insulin in the management of gestational diabetes: a meta-analysis. PLoS One 2017;12(8): e0182488. [PubMed: 28771572]

66. Senat MV, Affres H, Letourneau A, et al. Effect of glyburide vs subcutaneous insulin on perinatal complications among women with gestational diabetes: a randomized clinical trial. JAMA 2018;319(17):1773-80. [PubMed: 29715355]

67. Eyal S, Easterling TR, Carr D, et al. Pharmacokinetics of metformin during pregnancy. Drug Metab Dispos 2010;38(5):833-40. [PubMed: 20118196]

68. Vanky E, Zahlsen K, Spigset O, et al. Placental passage of metformin in women with polycystic ovary syndrome. Fertil Steril 2005;83(5):1575-8. [PubMed: 15866611]

69. Wouldes TA, Battin M, Coat S, et al. Neurodevelopmental outcome at 2 years in offspring of women randomised to metformin or insulin treatment for gestational diabetes. Arch Dis Child Fetal Neonatal Ed 2016;101(6):F488-93. [PubMed: 26912348]

70. Barbour LA, Scifres C, Valent AM, et al. A cautionary response to SMFM statement: pharmacological treatment of gestational diabetes. Am J Obstet Gynecol 2018;219(4):367.e1-e7. [PubMed: 29959933]

71. Hanem LGE, Stridsklev S, Juliusson PB, et al. Metformin use in PCOS pregnancies increases the risk of offspring overweight at 4 years of age: follow-up of two RCTs. J Clin Endocrinol Metab 2018;103(4):1612-21. [PubMed: 29490031]

72. Rowan JA, Rush EC, Plank LD, et al. Metformin in gestational diabetes: the offspring follow-up (MiG TOFU): body composition and metabolic outcomes at 7-9 years of age. BMJ Open Diabetes Res Care 2018;6(1):e000456.

73. Rowan JA, Hague WM, Gao W, et al. Metformin versus insulin for the treatment of gestational diabetes. N Engl J Med 2008;358(19):2003-15. [PubMed: 18463376]

74. Society of Maternal-Fetal Medicine Publications Committee. SMFM statement: pharmacological treatment of gestational diabetes. Am J Obstet Gynecol 2018; 218(5):B2-4.

75. Feig DS, Donovan LE, Corcoy R, et al. Continuous glucose monitoring in pregnant women with type 1 diabetes (CONCEPTT): a multicentre international randomised controlled trial. Lancet 2017;390(10110):2347-59. [PubMed: 28923465]

76. Yu F, Lv L, Liang Z, et al. Continuous glucose monitoring effects on maternal glycemic control and pregnancy outcomes in patients with gestational diabetes mellitus: a prospective cohort study. J Clin Endocrinol Metab 2014;99(12):4674-82. [PubMed: 25057872]

77. Wei Q, Sun Z, Yang Y, et al. Effect of a CGMS and SMBG on maternal and neonatal outcomes in gestational diabetes mellitus: a randomized controlled trial. Sci Rep 2016;6:19920. [PubMed: 26814139]

78. Murphy HR, Elleri D, Allen JM, et al. Pathophysiology of postprandial hyperglycaemia in women with type 1 diabetes during pregnancy. Diabetologia 2012; 55(2):282-93. [PubMed: 22080230] 


\section{KEY POINTS}

- $\quad$ Although it is well established that women with gestational diabetes mellitus (GDM) are at high risk for future development of T2DM, vigorous debate regarding the value of detecting and treating GDM persists.

- $\quad$ The Hyperglycemia and Adverse Pregnancy Outcome (HAPO) study showed that maternal hyperglycemia less severe than that in diabetes mellitus is associated with increased risks of adverse pregnancy outcomes.

- Increased rates of adiposity and disorders of glucose metabolism in peripubertal offspring exposed to GDM have been demonstrated.

- GDM treatment clearly reduces adverse pregnancy outcomes, although the impact of GDM treatment on long-term offspring outcomes remains to be determined.

- Insulin is considered the first-line pharmacologic treatment and is added when glycemic goals are not met with nutritional modifications. Oral agent use is controversial, as data on long-term offspring outcomes are lacking. 
$\longrightarrow$ Fasting glucose $\longrightarrow$ - $1 \cdot \mathrm{H}$ glucose $\longrightarrow 2 \cdot \mathrm{H}$ glucose

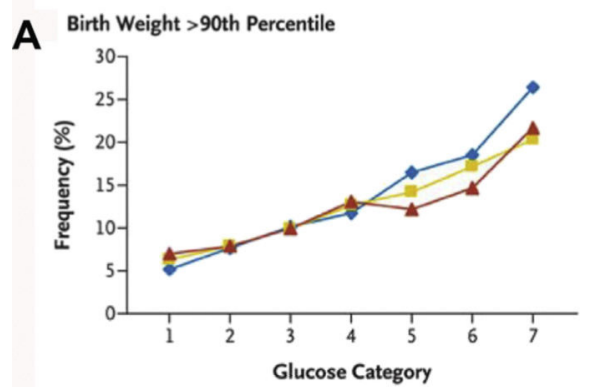

B Primary Cesarean Section

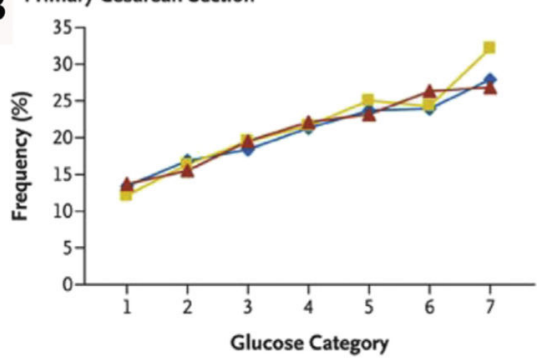

C Clinical Neonatal Hypoglycemia

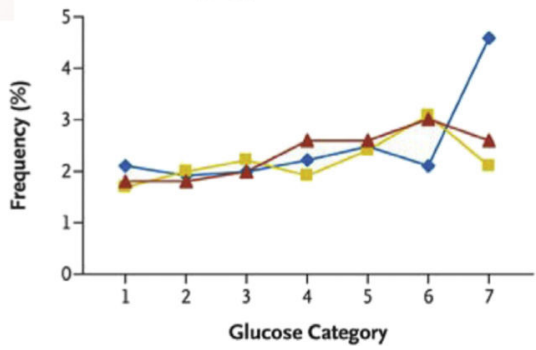

D Cord-Blood Serum C Peptide >90th Percentile

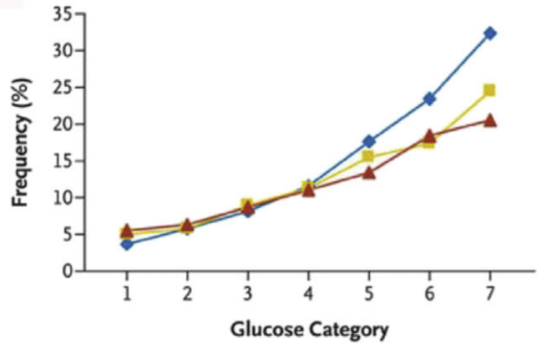

Fig. 1.

Frequency of primary outcomes across the glucose categories of fasting, 1-hour, and 2-hour values in a 75-g OGTT. $(A)$ Birth weight $>90$ th percentile. $(B)$ Primary cesarean delivery. (C) Clinical neonatal hypoglycemia. $(D)$ Cord blood serum c-peptide $>90$ th percentile. (From HAPO Study Cooperative Research Group, Metzger BE, Lowe LP, et al. Hyperglycemia and adverse pregnancy outcomes. N Engl J Med 2008;358(19):1991-2002; with permission.) 


\section{Table 1}

Treatment of mild gestational diabetes mellitus reduces adverse outcomes

\begin{tabular}{|lll|}
\hline Outcome & ACHOIS $^{a}$ & MFMU $^{b}$ \\
\hline Birth weight & $\downarrow$ & $\downarrow$ \\
\hline Large for gestational age & $\downarrow$ & $\downarrow$ \\
\hline Macrosomia & $\downarrow$ & $\downarrow$ \\
\hline Preeclampsia & $\downarrow$ & $\downarrow$ \\
\hline Cesarean delivery & - & $\downarrow$ \\
\hline Shoulder dystocia & - & $\downarrow$ \\
\hline
\end{tabular}

'indicates no difference between outcome in the intervention and observation participants.

$\downarrow$,indicates reduced outcome rate or mean.

${ }^{a}$ Australian Carbohydrate Intolerance Study. ${ }^{12}$

${ }^{b}$ Maternal Fetal Medicine Unit Network Study. 13

Data from Crowther CA, Hiller JE, Moss JR, et al. Effect of treatment of gestational diabetes mellitus on pregnancy outcomes. N Engl J Med. 2005;352(24):2477-2486 and Landon MB, Spong CY, Thom E, et al. A multicenter, randomized trial of treatment for mild gestational diabetes. N Engl J Med. 2009;361(14):1339-1348 


\section{Table 2}

Weighted distribution and glucose and BMI categories among women age 20-44 years, United States, 19761980 and 2007-2010

\begin{tabular}{|lll|}
\hline & \multicolumn{2}{l|}{ Weighted Percent (Standard Error) } \\
\hline Diabetes/BMI status $^{\boldsymbol{a}}$ & $\mathbf{1 9 7 6 - 1 9 8 0}$ & $\mathbf{2 0 0 7 - 2 0 1 0}$ \\
\hline Diagnosed diabetes $^{b}$ & $1.2(0.20)$ & $2.3(0.29)$ \\
\hline Undiagnosed diabetes $^{c}$ & $1.2(0.40)$ & $2.6(0.48)$ \\
\hline Undiagnosed prediabetes $^{c}$ & $11.9(1.15)$ & $24.0(1.87)$ \\
\hline Normal glucose levels $^{c}$ & $85.8(1.23)$ & $71.2(2.11)$ \\
\hline Obese & $12.1(1.05)$ & $32.7(1.79)$ \\
\hline Overweight & $21.6(1.67)$ & $26.4(1.67)$ \\
\hline Normal & $66.3(1.80)$ & $40.9(2.30)$ \\
\hline
\end{tabular}

Women currently pregnant were excluded from the analysis.

Abbreviation: BMI, body mass index (weight/height in $\mathrm{kg} / \mathrm{m}^{2}$ ).

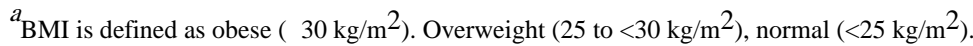

$b_{\text {Diagnosed diabetes is self-reported. }}$

${ }^{c}$ Undiagnosed diabetes, prediabetes, and normal glucose levels are defined by fasting plasma glucose or 2-hour plasma glucose from an oral glucose tolerance test using American Diabetes Association cutpoints.

From Metzger BE, Buchanan TA. Gestational diabetes. In: Cowie CC, CS, Menke A, Cissell MA, Eberhardt MS, Meigs JB, Gregg EW, Knowler WC, Barrett-Connor E, Becker DJ, Brancati FL, Boyko EJ, Herman WH, Howard BV, Narayan KMV, Rewers M, Fradkin JE, ed. Diabetes in America, 3rd ed. Bethesda, MD: National Institutes of Health, NIH Pub No. 17-1468; 2018:4-1-17. 
Table 3

Diagnosis of gestational diabetes

\begin{tabular}{|c|c|c|c|c|}
\hline \multirow[b]{2}{*}{$\begin{array}{l}\text { Glucose Value, } \\
\text { mg/dL }\end{array}$} & \multicolumn{3}{|c|}{$100 \mathrm{~g}$ Oral Glucose Load ${ }^{a}$} & \multirow{2}{*}{$\begin{array}{l}75 \text { g Oral Glucose Load } \\
\text { IADPSG }^{15} \text { Plasma } \\
\text { Enzymatic }^{e}\end{array}$} \\
\hline & $\begin{array}{l}\text { O'Sullivan-Mahan' } \\
\text { Whole Blood }^{b}\end{array}$ & $\begin{array}{l}\text { NDDG }^{4} \text { Plasma- } \\
\text { Autoanalyzer }\end{array}$ & $\begin{array}{l}\text { Carpenter-Coustan }{ }^{14} \\
\text { Plasma-Glucose } \\
\text { Oxidase }^{d}\end{array}$ & \\
\hline Fasting & 90 & 105 & 95 & 92 \\
\hline 1-h & 165 & 190 & 180 & 180 \\
\hline 2-h & 145 & 165 & 155 & 153 \\
\hline 3-h & 125 & 145 & 140 & NA \\
\hline
\end{tabular}

Abbreviations: IADPSG, International Association of Diabetes and Pregnancy Study Groups; NDDG, National Diabetes Data Group.

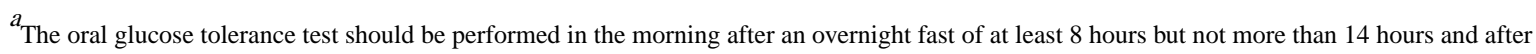
at least 3 days of unrestricted diet ( $\geq 150 \mathrm{~g}$ carbohydrate per day) and physical activity.

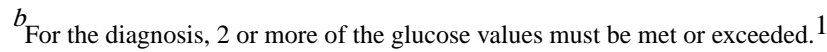

${ }^{c}$ For the diagnosis, 2 or more of the glucose values must be met or exceeded. ${ }^{4}$

${ }^{d}$ For the diagnosis, 2 or more of the glucose values must be met or exceeded. ${ }^{14}$

$e^{e}$ For the diagnosis, 1 or more of the glucose values must be met or exceeded. ${ }^{15}$ 


\section{Table 4}

Potential adverse outcomes in offspring exposed to gestational diabetes mellitus

\begin{tabular}{|ll}
\hline Fetus & Malformations, stillbirth, chorioamnionitis, birth asphyxia, preterm birth, macrosomia \\
\hline Neonate & $\begin{array}{l}\text { Large for gestational age, birth injury, hypoglycemia, respiratory distress syndrome/transient tachypnea, polycythemia and } \\
\text { hyperbilirubinemia, hypocalcemia }\end{array}$ \\
\hline Child & Neurodevelopmental impairments, obesity, increased adiposity, insulin resistance, impaired glucose tolerance \\
\hline Adult & Obesity, insulin resistance, impaired glucose tolerance, type 2 diabetes mellitus \\
\hline
\end{tabular}

Fetus Malformations, stillbirth, chorioamnionitis, birth asphyxia, preterm birth, macrosomia

Neonate Large for gestational age, birth injury, hypoglycemia, respiratory distress syndrome/transient tachypnea, polycythemia and

Child Neurodevelopmental impairments, obesity, increased adiposity, insulin resistance, impaired glucose tolerance

Obesity, insulin resistance, impaired glucose tolerance, type 2 diabetes mellitu 


\section{Table 5}

Calculating total daily insulin requirement of a pregnant woman during different trimesters of pregnancy

\begin{tabular}{|ll|}
\hline Weeks Gestation & Total Daily Insulin Requirement (units/day) \\
\hline $1-13$ & Pregnant woman's weight in $\mathrm{kg} \times 0.7$ \\
\hline $14-26$ & Pregnant woman's weight in $\mathrm{kg} \times 0.8$ \\
\hline $27-37$ & Pregnant woman's weight in $\mathrm{kg} \times 0.9$ \\
\hline 38 to delivery & Pregnant woman's weight in $\mathrm{kg} \times 1.0$ \\
\hline
\end{tabular}

Based on average total daily insulin requirements in pregnant women with preexisting diabetes mellitus.

From Castorino K, Paband R, Zisser H, et al. Insulin pumps in pregnancy: using technology to achieve normoglycemia in women with diabetes. Curr Diab Rep. 2012;12(1):53-59; with permission. 